\title{
Review: drugs do not improve symptoms in urinary urge incontinence and may have side effects
}

Haeusler G, Leitich H, van Trotsenburg M, et al. Drug therapy of urinary urge incontinence: a systematic review. Obstet
Gynecol 2002;100:1003-16.

\section{QUESTION: Is drug therapy effective for urinary urge incontinence (UI)?}

\section{Data sources}

Studies published up to October 2000 were identified by searching Medline (from 1966), EMBASE/Excerpta Medica (from 1989), and the Cochrane Controlled Trials Register.

\section{Study selection}

Original English language studies were selected if they were randomised placebo controlled trials of drug therapies other than hormone therapy in patients with UI confirmed by urodynamic assessment and outcomes included $\geq 1$ of subjective improvement, results of a urodynamic evaluation, or adverse effects.

\section{Data extraction}

3 independent investigators extracted data on number of patients, inclusion and exclusion criteria, type of drug, and outcomes. Quality of individual trials was assessed on the basis of the randomisation process, patient exclusions after randomisation, and patient compliance.

\section{Main results}

47 trials met the selection criteria, but 11 trials of terodiline were excluded from analysis because it was withdrawn from the market. Sample sizes in the remaining 36 trials ranged from 20-316. Meta-analysis was not done because of heterogeneity among trials. Only drugs that were assessed in $>1$ trial are reported here. Results for the anticholinergic drugs oxybutinin, emepronium, and tolterodine are summarised in the table.

12 trials assessed alternative drug regimens. Flavoxate had no effect on symptoms in 1 of 1 trial $(n=38)$ or adverse effects in 2 of 2 trials $(n=91)$. Flurbiprofen improved symptoms in 1 of 1 trial $(n=58)$, but increased adverse effects in 1 of 1 trial $(\mathrm{n}=61)$ and had no effect on dry mouth in 2 of 2 trials $(n=121)$ or adverse effects that stopped treatment in 2 of 2 trials $(n=126)$.

\section{Conclusion}

Limited evidence suggests that drugs commonly used for incontinence-oxybutinin, emepronium, tolterodine, and flavoxate-are either ineffective or their low rate of effectiveness is counterbalanced by an increase in specific adverse effects.

\section{COMMENTARY}

Despite decades of using anticholinergic drugs for UI, few well designed, controlled trials support the efficacy of these drugs. Haeusler et al identified double blind trials that were published up to October 2000. Only 8 of 36 trials enrolled $>100$ patients, and outcomes were mostly based on subjective reports by patients rather than urodynamic results. Trials of non-pharmacological therapies ${ }^{1}$ that incorporated independent drug-placebo comparison arms that might have been included were not. 3 studies quoted by the US Public Health Service Clinical Practice Guideline ${ }^{2}$ as establishing the effectiveness of oxybutinin were not mentioned.

Only a small proportion of the trials with outcome data reported significant benefits. This may reflect small sample sizes, heterogeneous patient populations, and a relatively high placebo response rate (approximately 40\% for reduction in incontinence episodes). ${ }^{1}$ Better results have been obtained with biofeedback and behavioural therapy in geriatric outpatients. ${ }^{1}$ These techniques are not currently available in routine clinical practice but perhaps should be part of our clinical training. None of the trials included elderly patients with dementia, a group with a high frequency of UI in whom delirium associated with anticholinergic agents is a major adverse effect.

An effective, safe, pharmacological solution for incontinence continues to escape us, but clinicians can at least rely on easily implemented guidelines for diagnostic stratification $^{2-3}$ and assist patients with treatment decisions, which may include a trial of medication.

Fitzhugh C Pannill III, MD, FACP Southbury Medical Associates Southbury, Connecticut, USA

1 Burgio KL, Locher JL, Goode PS, et al. Behavioral vs drug reatment for urge urinary incontinence in older women: a randomized controlled tral. JAMA 1998,280.1995-2000.

2 Fantl JA, Newman DK, Colling J. Urinary incontinence in adults: acute and chronic management. Clinical Practice Guideline, No 2. AHCPR Publication No 95-0682. Rockville, MD: Agency for Health Care Policy and Research, 1996. http://www.ahcpr.gov/research/may96/dept5.htm

3 Resnick NM. Urinary incontinence. In: Cassel CK, Leipzig $\mathrm{RM}$, Cohen HJ, et al, editors. Geriatric medicine: an evidence based approach. 4th edition. New York: Springer, 003:931-55.

Effectiveness of anticholinergic drugs for urinary urge incontinence

\begin{tabular}{lllll} 
Outcomes & Oxybutinin & Emepronium & Tolterodine \\
Symptoms & Improved in $2(n=137)$ of $5(n=456)$ trials & Improved in $1(n=36)$ of 5 trials $(n=192)$ & No difference in 2 of 2 trials $(n=449)$ \\
\hline Bladder stability & No difference in 2 of 2 trials $(n=145)$ & No difference in 1 of 1 trial $(n=40)$ & Not assessed \\
\hline Adverse effects & Increased in $3(n=507)$ of 4 trials $(n=546)$ & Increased in $1(n=36)$ of 4 trials $(n=156)$ & No difference in 4 of 4 trials $(n=587)$ & Increased in $2(n=491)$ of 5 trials $(n=903)$ \\
\hline $\begin{array}{l}\text { Dry mouth } \\
\text { Adverse effects that } \\
\text { stopped treatment }\end{array}$ & Increased in $5(n=662)$ of 7 trials $(n=845)$ & No difference in 4 of 4 trials $(n=156)$ & No difference in 4 of 4 trials $(n=823)$ \\
\hline
\end{tabular}

